\title{
Adenylate kinase-independent thiamine triphosphate accumulation under severe energy stress in Escherichia coli
}

\author{
Tiziana Gigliobianco ${ }^{1}$, Bernard Lakaye ${ }^{1}$, Alexander F Makarchikov ${ }^{1,2}$, \\ Pierre Wins ${ }^{1}$ and Lucien Bettendorff*1
}

\author{
Address: ${ }^{1}$ Center for Cellular and Molecular Neurobiology, University of Liège, Liège, Belgium and ${ }^{2}$ Chemical Department, Grodno State \\ Agricultural University, Grodno, Belarus \\ Email: Tiziana Gigliobianco - t.gigliobianco@ulg.ac.be; Bernard Lakaye - B.Lakaye@ulg.ac.be; \\ Alexander F Makarchikov - a_makarchikov@yahoo.com; Pierre Wins - P.Wins@ulg.ac.be; Lucien Bettendorff* - L.Bettendorff@ulg.ac.be \\ * Corresponding author
}

Published: 23 January 2008

BMC Microbiology 2008, 8:16 doi:10.1186/1471-2180-8-16
Received: 21 August 2007

Accepted: 23 January 2008

This article is available from: http://www.biomedcentral.com/I47I-2/80/8/16

(c) 2008 Gigliobianco et al; licensee BioMed Central Ltd.

This is an Open Access article distributed under the terms of the Creative Commons Attribution License (http://creativecommons.org/licenses/by/2.0), which permits unrestricted use, distribution, and reproduction in any medium, provided the original work is properly cited.

\begin{abstract}
Background: Thiamine triphosphate (ThTP) exists in most organisms and might play a role in cellular stress responses. In E. coli, ThTP is accumulated in response to amino acid starvation but the mechanism of its synthesis is still a matter of controversy. It has been suggested that ThTP is synthesized by an ATP-dependent specific thiamine diphosphate kinase. However, it is also known that vertebrate adenylate kinase I catalyzes ThTP synthesis at a very low rate and it has been postulated that this enzyme is responsible for ThTP synthesis in vivo.
\end{abstract}

Results: Here we show that bacterial, as vertebrate adenylate kinases are able to catalyze ThTP synthesis, but at a rate more than $10^{6}$-fold lower than ATP synthesis. This activity is too low to explain the high rate of ThTP accumulation observed in E. coli during amino acid starvation. Moreover, bacteria from the heat-sensitive CV2 strain accumulate high amounts of ThTP ( $>50 \%$ of total thiamine) at $37^{\circ} \mathrm{C}$ despite complete inactivation of adenylate kinase and a subsequent drop in cellular ATP.

Conclusion: These results clearly demonstrate that adenylate kinase is not responsible for ThTP synthesis in vivo. Furthermore, they show that E. coli accumulate large amounts of ThTP under severe energy stress when ATP levels are very low, an observation not in favor of an ATPdependent mechanisms for ThTP synthesis.

\section{Background}

Thiamine (vitamin B1) is an essential compound for all known life forms. The well-known cofactor thiamine diphosphate (ThDP) [1] is the major form of thiamine in most cell types. Thiamine monophosphate (ThMP) and free thiamine, which have no known physiological function, account for only a few percent of the total thiamine content. Thiamine triphosphate (ThTP) is generally a minor component but it has been found in most organisms, from prokaryotes to mammals [2]. In vertebrates, ThTP has been found to activate a large conductance anion channel [3] and to phosphorylate certain proteins [4], suggesting that it may be involved in a new cellular signaling pathway. 
In animal tissues, cellular concentrations of ThTP generally remain relatively constant and low $(0.1$ to $1 \mu \mathrm{M})$. In contrast, in the enterobacterium E. coli, ThTP content strongly depends on environmental conditions. ThTP is nearly undetectable in rich LB medium, but in minimal medium devoid of amino acids, the addition of a carbon source such as glucose or pyruvate induces a rapid accumulation of ThTP and its intracellular concentration may transiently exceed $10 \mu \mathrm{M}$ [5]. Overexpression in E. coli of a specific soluble mammalian thiamine triphosphatase (ThTPase), that we previously characterized [6-8], prevented ThTP accumulation and induced the appearance of an intermediate plateau in bacterial growth [5]. This suggested that ThTP may be required for the rapid adaptation of bacteria to amino acid starvation. On the other hand, when the bacteria were incubated in minimal medium devoid of any carbon source, we noticed the appearance of a new compound that was identified as adenosine thiamine triphosphate (AThTP) [9]. Interestingly, ThTP and AThTP never accumulate simultaneously in high amounts, suggesting that the two compounds may act as specific alarmones, responding to different conditions of cellular stress.

While AThTP is synthesized according to the recently established reaction ThDP + ADP $($ ATP $) \Leftrightarrow$ AThTP $+P_{i}$ $\left(\mathrm{PP}_{\mathrm{i}}\right)$ [10], the enzymatic mechanism of ThTP synthesis remains unclear. It has been shown that vertebrate adenylate kinase 1 (AK1, myokinase, EC 2.7.4.3) catalyzes the synthesis of ThTP at a low rate according to the reaction ThDP + ADP $\Leftrightarrow$ ThTP + AMP [11]. Although, the in vivo synthesis of ThTP by AK1 was shown to occur in chicken skeletal muscle [12], we have found that AK1 knockout mice have normal ThTP levels (even in skeletal muscle). This suggests that ThTP synthesis by AK1 is not of physiological relevance in mammals [13], which does not rule out that other mammalian AK isoforms [14] may be responsible for ThTP synthesis. Here we show that two bacterial AKs are able to catalyze ThTP synthesis at a low rate but our data strongly suggest that this enzyme is not responsible for the in vivo accumulation of ThTP in E. coli in response to amino acid starvation.

\section{Results and Discussion}

We have previously reported [5] that when E. coli cells are transferred to a minimal medium containing glucose, they accumulate ThTP at a high rate (about 100 pmol per $\mathrm{mg}$ protein in $10 \mathrm{~min}$ ). As $\mathrm{AK}$ is a possible candidate for catalyzing ThTP synthesis, it is important to determine whether bacterial AKs are able to catalyze this reaction and, if they do, to know whether the specific activity of, in particular, E. coli AK is sufficient to account for the relatively high rate of ThTP production measured in vivo in this organism.

We first tested the ability of commercially available AK from B. stearothermophilus to synthesize ThTP from ThDP and ADP. The enzyme was indeed able to catalyze this reaction at a rate of $0.2 \mathrm{pmol}$ ThTP formed per min per mg protein under our assay conditions. For the physiological reaction $2 \mathrm{ADP} \Leftrightarrow \mathrm{ATP}+\mathrm{AMP}$, we found 1.8

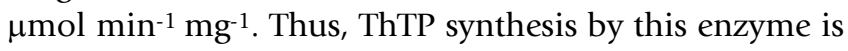
$10^{7}$ times slower than ATP synthesis (Table 1 ).

E. coli has only one AK isoform [15]. We overexpressed this protein in E. coli BL21 $\lambda$ DE3 under the control of the lac operon. As shown in Fig. 1A, the transformed bacteria produced high amounts of AK after induction by IPTG. At the same time, the ATP-synthesizing activity of E. coli AK was increased about 1000-fold (from $67 \mathrm{nmol} \mathrm{min}^{-1} \mathrm{mg}^{-1}$

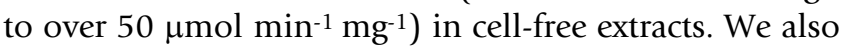
observed that these bacteria began to accumulate ThTP shortly after addition of IPTG (Fig. 1B), suggesting that ThTP synthesis is a direct consequence of AK overexpression. After 3 hours, the [ThTP]/[ThDP] ratio reached a relatively high value around 0.55 .

However, it is important to emphasize that in contrast to the normal BL21 strain, which accumulates ThTP only in the presence of glucose in amino acid-depleted medium, E. coli overexpressing AK accumulated ThTP in rich LB medium and glucose was not required. Furthermore, IPTG did not induce ThTP synthesis in control bacteria carrying an empty plasmid (not shown). These results suggest that E. coli AK constitutively synthesizes ThTP and that there is no physiological control of this reaction. The present results are very similar to those of Shioda et al.

Table I: Comparison of ThTP- and ATP-synthesizing activity of adenylate kinases from various sources.

\begin{tabular}{|c|c|c|c|}
\hline Sources & ThTP synthesis (pmol $\mathrm{min}^{-1} \mathrm{mg}^{-1}$ ) & ATP synthesis $\left(\mathrm{pmol} \mathrm{min}^{-1} \mathrm{mg}^{-1}\right)$ & Ratio ATP/ThTP \\
\hline AK B. stearothermophilus ${ }^{\mathrm{a}}$ & $0.2(\mathrm{pH} 6.5)$ & $1.8 \times 10^{6}$ & $9 \times 10^{6}$ \\
\hline AK E. colia & 35 & $137 \times 10^{6}$ & $3.9 \times 10^{6}$ \\
\hline AKI pig skeletal muscleb & 570 & $1055 \times 10^{6}$ & $1.8 \times 10^{6}$ \\
\hline AKI chicken skeletal musclec & 60 & $155 \times 10^{6}$ & $2.6 \times 10^{6}$ \\
\hline lbid. & $265(\mathrm{pH} \mathrm{l0})$ & $155 \times 10^{6}$ & $0.6 \times 10^{6}$ \\
\hline
\end{tabular}

ThTP synthesis was measured at $\mathrm{pH} 7.5$, except when indicated, as described in the Methods section. The assays for ATP synthesis were done at $\mathrm{pH}$ 7.5. a, this study; b, [II]; c, [16] 

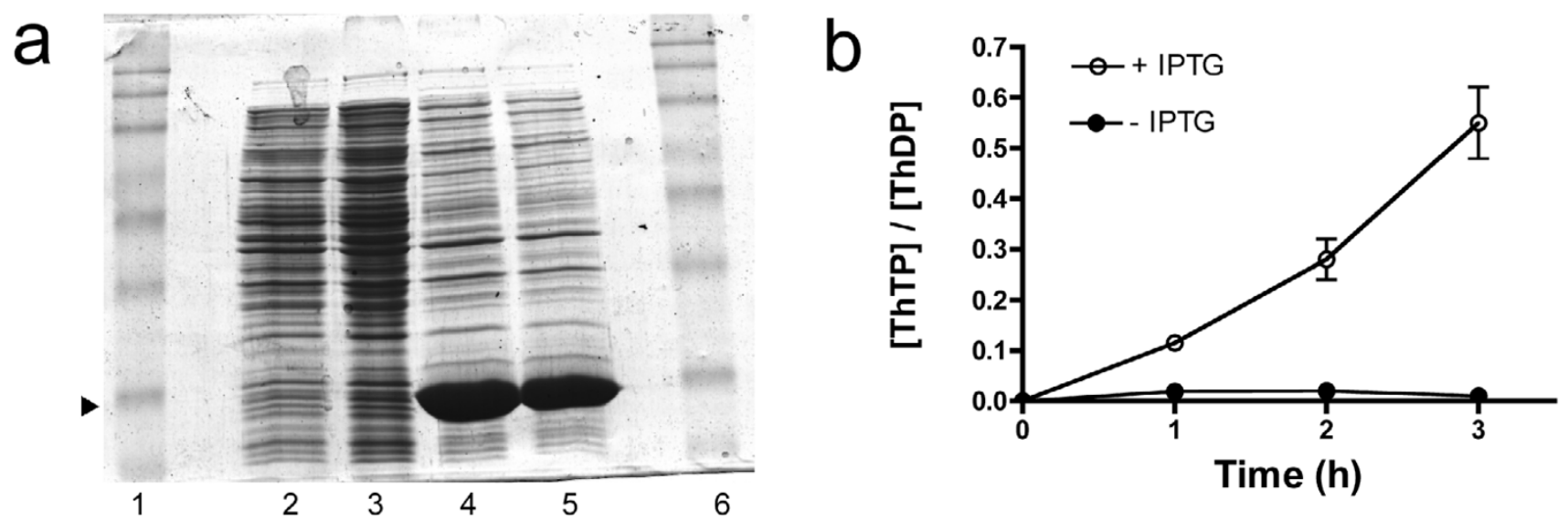

Figure I

Overexpression of E. coli AK induces cellular ThTP accumulation. Overexpression of E. coli AK induces cellular ThTP accumulation. Strain BL2I $\lambda$ DE3 bacteria carrying PET-2la $(+)$ with the E. coli AK cDNA were grown ovenight in LB medium in the presence of ampicillin $(\mathrm{I} \mathrm{mg} / \mathrm{ml})$. The cultures were diluted until $A_{600}=0.6-0.8$ and the bacteria were grown in the absence or presence of IPTG $(\mathrm{I} \mathrm{mM})$ for $3 \mathrm{~h}\left(37^{\circ} \mathrm{C}, 250 \mathrm{rpm}\right)$. The bacteria were sonicated, centrifuged and the supernatant was used for electrophoresis $(A)$ and ThTP estimation (B). (A) The presence of a band corresponding to AK was checked on a I2\% SDS-PAGE followed by Coomassie blue staining (a, lanes 2, 3 without IPTG and lanes 4, 5 with IPTG). Lanes I and 6 contain the molecular weight markers (Prestained Protein Ladder, Invitrogen). Overexpessed protein migrated at $M_{r} 25000$ (arrowhead) for a theoretical molecular mass of 23559 based on amino acid composition [I5]. (B) Effect of E. coli AK overexpression on the intracellular $[$ ThTP]/[ThDP] ratio. Aliquots were taken at various times for the determination of thiamine derivatives. The results are expressed as mean \pm SD for 3 experiments. At the same time ATP synthesizing activity of AK increased by a factor 1000 in cell-free extracts (not shown).

[16] who overexpressed chicken AK1 in E. coli and also observed an important accumulation of ThTP after induction by IPTG in rich LB medium. We measured the ThTPsynthesizing activity of the overexpressed bacterial AK in vitro, in the supernatant obtained after sonication and centrifugation of the bacteria. Under our assay conditions the rate was $35 \mathrm{pmol} \mathrm{min}^{-1} \mathrm{mg}^{-1}$, while the rate of ATP synthesis was $137 \mu \mathrm{mol} \mathrm{min}^{-1} \mathrm{mg}^{-1}$. Thus, ThTP synthesis catalyzed by E. coli AK is over 6 orders of magnitude slower than ATP synthesis (Table 1). A similar ratio between ThTP and ATP synthesis was also previously reported for porcine [11] and chicken AK1 [16] and for B. stearothermophilus AK (this study).

We conclude that the three types of AK investigated (AK1 from vertebrates, $A K$ from $B$. stearothermophilus and $A K$ from E. coli) are able to catalyze ThTP synthesis from ThDP and ADP, but the reaction is over $10^{6}$ times slower than ATP synthesis. It is thus possible that the catalysis of ThTP synthesis is a general property of AKs, but this reaction is not likely to be of physiological importance.

It is interesting to compare the rate of ThTP synthesis by AKs in vitro with the maximum rate observed in vivo. The latter is about $10 \mathrm{pmol} \mathrm{min}^{-1} \mathrm{mg}^{-1}$ [5] for normal BL21 bacteria in minimal medium containing $10 \mathrm{mM}$ glucose.
In cell-free extracts from BL21 bacteria, we found that the specific activity for AK-catalyzed ATP synthesis was 67 nmol $\mathrm{min}^{-1} \mathrm{mg}^{-1}$. Assuming that the rate of ThTP synthesis is $10^{6}$ times lower, it would be about $0.05-0.10 \mathrm{pmol}$ $\mathrm{min}^{-1} \mathrm{mg}^{-1}$, two orders of magnitude lower than the accumulation measured in vivo. But after induction by IPTG, AK expression is increased about 1000-fold (Fig. 1A), largely enough to account for the observed ThTP accumulation (Fig 1B). However, the ThTP-forming activity of bacterial AK appears to be constitutive and to escape physiological control. Nevertheless, it could still be argued that bacterial AK is responsible for ThTP synthesis in vivo if one assumes that the enzyme can be activated ( $\geq 100$-fold) by some unknown factor(s).

The following experiment strongly suggests that a different, AK-independent mechanism is responsible for ThTP synthesis in E. coli. We used the CV2 strain $[15,17]$ containing a heat-sensitive AK. CV2 E. coli grow normally at the permissive temperature $\left(25-30^{\circ} \mathrm{C}\right)$ but shifting them to $37^{\circ} \mathrm{C}$ leads to a rapid inactivation of AK and the subsequent drop in energy charge (from 0.9 to $0.2,[18]$ ), causing a progressive decrease in the number of viable cells. As shown in Fig. 2A, CV2 bacteria grown at $25^{\circ} \mathrm{C}$ respond normally by producing ThTP when they are transferred to minimal medium containing glucose. However, high 

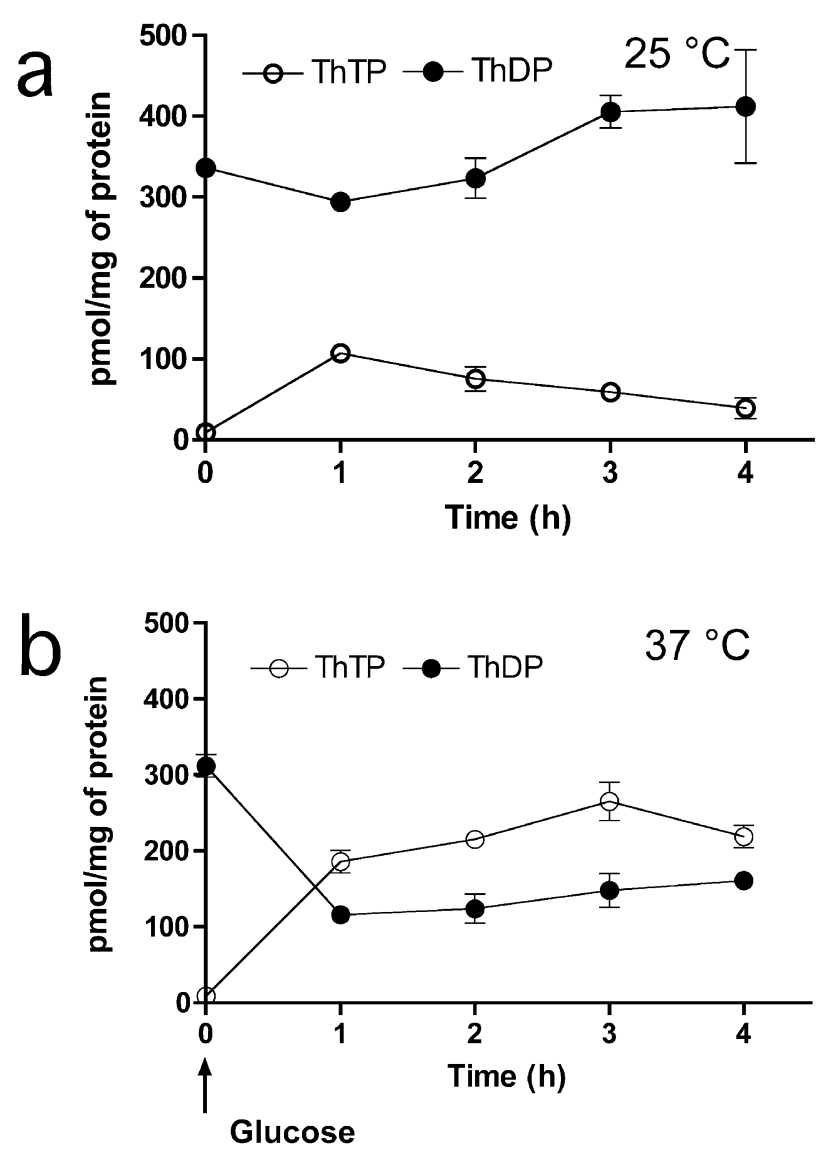

Figure 2

Effect of AK inactivation in the heat-sensitive E. coli strain CV2 on the intracellular ThTP and ThDP concentrations. Effect of AK inactivation in the heat-sensitive E. coli strain CV2 on the intracellular ThTP and ThDP concentrations. The bacteria were grown at $25^{\circ} \mathrm{C}$ in LB medium, suspended in minimal $M 9$ medium and preincubated for four hours either at $25^{\circ} \mathrm{C}(\mathrm{A})$ or at $37^{\circ} \mathrm{C}(\mathrm{B})$. After $60 \mathrm{~min}$ at $37^{\circ} \mathrm{C}$, no significant $\mathrm{AK}$ activity was detectable, while it remained high at $25^{\circ} \mathrm{C}$ (not shown). Then glucose was added at 25 and $37^{\circ} \mathrm{C}$ (zero time) and aliquots were taken after various time intervals for the determination of thiamine derivatives. The results are expressed as mean $\pm S D(n=3)$.

ThTP levels were maintained for at least 2 hours, while in BL21 bacteria incubated at $37^{\circ} \mathrm{C}$, ThTP accumulation was transient [5]. When the CV2 bacteria were shifted to $37^{\circ} \mathrm{C}$, they lost all detectable AK activity after less than 2 hours as previously reported [18]. However, addition of glucose under these conditions led to an unexpectedly high production of ThTP. As shown in Fig. 2B, the cellular ThTP content after 2 hours even exceeded ThDP content while the total amount of phosphorylated thiamine, i.e. [ThDP] $+[$ ThTP], remained roughly constant.
These results show that high amounts of ThTP (60\% of total thiamine) can be synthesized from ThDP in the absence of AK activity. The phosphate donor is therefore unlikely to be ADP. Another obvious candidate is ATP. However, when we incubate $\mathrm{CV} 2$ bacteria at $37^{\circ} \mathrm{C}$ we find that, even in the presence of glucose, the cellular ATP concentration is less than $10 \%$ of the one found in normal BL21 bacteria or CV2 bacteria at $25^{\circ} \mathrm{C}$ (data not shown) as previously observed [18]. This is not in favor of the hypothesis that ATP is the phosphate donor except if the putative ThDP kinase catalyzing this reaction has a very high affinity for ATP.

Actually, there is so far no evidence that E. coli contains a ThDP kinase. In cell-free bacterial extracts, we attempted to measure ThTP formation from ThDP and ATP under various conditions but we were unable to detect any net synthesis of ThTP. It thus appears that the phosphate donor for ThDP phosphorylation may be neither ADP nor ATP, at least in E. coli. In eukaryotic organisms, it has long been thought that ThTP is synthesized by a soluble ThDP kinase: this enzyme was supposed to exist in mammals [19-22] and in yeast $[23,24]$. The enzyme was obtained in pure form from yeast [23] but, like other preparations of ThDP kinase, it had a very low specific activity $\left(\mathrm{k}_{\mathrm{cat}}\right.$ about $1 \mathrm{~min}^{-1}$ ). Moreover, it is not certain that the reaction product was authentic ThTP. Indeed, it could well be that the compound synthesized was in fact AThTP which can be synthesized from ThDP and ATP or ADP by a soluble enzyme complex [10]. Thus, there is no conclusive evidence that ThTP can be synthesized from ThDP + ATP, either in animals or in microorganisms. Also, it is probable that in skeletal muscle where AK1 activity is very high, the latter may contribute to a significant synthesis of cytosolic ThTP, especially in those species where soluble ThTPase activity is absent such as in electric organ $[25,26]$, chicken [12] and pig skeletal muscle [27]. Indeed, electric organs and bird tissues contain no soluble ThTPase and pig tissues express a catalytically inefficient ThTPase [28].

\section{Conclusion}

In conclusion, the present results show that, in the heatsensitive CV2 strain as in normal E. coli, ThTP accumulation occurs through an adenylate kinase-independent mechanism. The bacteria produce ThTP when they are transferred to minimal medium devoid of amino acids but containing glucose. The requirement for glucose does not appear to be related to its ability to generate ATP. Indeed, we find the highest accumulation of ThTP in CV2 cells at $37^{\circ} \mathrm{C}$ when the energy charge is very low. It is remarkable that under such stressful conditions, the cells still devote a large part of their ThDP (an indispensable cofactor for oxidative metabolism) and a significant amount of free energy to produce ThTP. At present, we cannot exclude that ThTP and possibly AThTP are inactive 
storage forms of ThDP. This hypothesis is however not very plausible as ThTP and AThTP accumulate under different and often opposing metabolic conditions. This would imply that ThDP could be stored under a different form dependent on the kind of stress involved. Therefore, it is more appealing to imagine that both compounds are some kind of alarmones or signalling molecules produced in response to different conditions of cellular stress.

\section{Methods \\ Materials}

B. stearothermophilus AK was from Sigma-Aldrich (StLouis, MO, USA). The heat-sensitive E. coli strain CV2 (CGSC strain \# 4682) [17] was obtained from the E. coli Genetic Resource Center (Yale University, New Haven, CT, U.S.A.) through N. Whitehead. It was grown at $25^{\circ} \mathrm{C}$ in LB medium (250 rpm).

\section{Growth and processing of bacteria}

The bacteria (E. coli BL21 strain) were grown overnight $\left(37^{\circ} \mathrm{C}, 250 \mathrm{rpm}\right)$ in $50-100 \mathrm{ml} \mathrm{LB}$ medium (tryptone, 10 $\mathrm{g} / \mathrm{l}$; yeast extract, $5 \mathrm{~g} / \mathrm{l} ; \mathrm{NaCl}, 10 \mathrm{~g} / \mathrm{l}$ at $\mathrm{pH}$ 7.0). Then the bacteria were centrifuged ( $5 \mathrm{~min} ; 5000 \times \mathrm{g}$ ) and suspended in the initial volume of fresh LB medium or in M9 minimal medium $\left(\mathrm{Na}_{2} \mathrm{HPO}_{4}, 6 \mathrm{~g} / \mathrm{l} ; \mathrm{KH}_{2} \mathrm{PO}_{4}, 3 \mathrm{~g} / \mathrm{l} ; \mathrm{NaCl}\right.$, $0.5 \mathrm{~g} / \mathrm{l} ; \mathrm{NH}_{4} \mathrm{Cl}, 1 \mathrm{~g} / \mathrm{l} ; \mathrm{CaCl}_{2}, 3 \mathrm{mg} / \mathrm{l} ; \mathrm{MgSO}_{4}, 1 \mathrm{mM}, \mathrm{pH}$ 7.0) either in the presence or the absence of $10 \mathrm{mM}$ glucose at $37^{\circ} \mathrm{C}$ with shaking $(250 \mathrm{rpm})$. After incubation, the bacteria were sedimented as above, the pellet was suspended in $12 \%$ trichloroacetic acid, the precipitated proteins were spun down $(15 \mathrm{~min}, 15000 \times \mathrm{g})$ and the pellet was dissolved in $0.8 \mathrm{~N} \mathrm{NaOH}$ for protein determination by the method of Peterson [29]. The supernatant was treated with diethyl ether and analyzed by HPLC for thiamine compounds [30]. ATP was determined using the ATP Bioluminescent Assay Kit from Sigma-Aldrich.

\section{Cloning and overexpression of $E$. coli adenylate kinase}

Genomic DNA was isolated from E. coli (BL21) and the coding sequence for adenylate kinase was amplified using Taq DNA polymerase and 40 cycles of denaturation $\left(95^{\circ} \mathrm{C}, 30 \mathrm{~s}\right)$, annealing $\left(58^{\circ} \mathrm{C}, 30 \mathrm{~s}\right)$ and elongation $\left(72^{\circ} \mathrm{C}, 60 \mathrm{~s}\right)$ using forward $\left(5^{\prime}\right.$-CACATATGCGTATCATTCTGCTTGGCGCT-3') and reverse (5'-CAAAGCTTAGCCGATTTTTTCCAGATCAGCG-3') primers. The PCR fragment was inserted into pGEM-T (Promega Corporation, Madison, WI, U.S.A.) by TA cloning. After sequencing, the AK coding sequence was recovered and ligated into the NdeI/HindIII sited of pET-21a(+) (Novagen, Madison, WI, U.S.A). The strain E. coli BL21 $\lambda$ DE3 was used for overexpression of $\mathrm{E}$. coli adenylate kinase.

\section{Determination of adenylate kinase activity}

The culture medium containing the bacteria $(1 \mathrm{ml})$ was centrifuged $\left(5000 \times \mathrm{g}, 15 \mathrm{~min}, 4^{\circ} \mathrm{C}\right)$ and the pellet was suspended in $500 \mu$ l Hepes-Na buffer ( $50 \mathrm{mM}, \mathrm{pH} 7.5$ ) containing $1 \mathrm{mM}$ EDTA. The samples were sonicated $3 \times$ 1 min on ice $(100 \mathrm{kHz})$ and centrifuged $(5000 \times \mathrm{g}, 10$ $\left.\min , 4^{\circ} \mathrm{C}\right)$. The supernatant was used as enzyme preparation. The incubation medium contained $50 \mathrm{mM}$ Tris/ $\mathrm{HCl}$ buffer (pH 7.5), $5 \mathrm{mM} \mathrm{MgCl}_{2}, 5 \mathrm{mM}$ ADP and the enzyme preparation at an appropriate dilution in a total volume of $100 \mu \mathrm{l}$. After $5 \mathrm{~min}$ at $37^{\circ} \mathrm{C}$, the reaction was stopped by addition of $100 \mu \mathrm{l}$ trichloroacetic acid (20\%). After extraction with diethyl ether, ATP was determined by bioluminescence. For the determination of the ThTP-synthesizing activity of adenylate kinase, the substrates were ADP (1 $\mathrm{mM})$ and ThDP $(0.1 \mathrm{mM})$ in Tris/HCl buffer $(\mathrm{pH} 7.5)$ for E. coli AK and Tris-maleate buffer ( $\mathrm{pH}$ 6.5) for B. stearothermophilus AK. The samples were incubated up to 24 hours and the ThTP synthesized was determined by HPLC [30].

\section{Authors' contributions}

TG did most of the experimental work described in the study. BL oversaw the cloning of E. coli AK and participated in the design of the study. AFM participated in the initial experimental work with bacterial adenylate kinases. PW participated in the design of the study and revised the manuscript. LB was the project leader, coordinated the study, participated in its design and wrote the final manuscript. All authors read and approved the final manuscript.

\section{Acknowledgements}

The authors wish to thank the "Fonds de la Recherche Fondamentale Collective" (FRFC) for grant 2.4558.04 to L.B. B.L. and L.B. are respectively Research Associate and Research Director at the "Fonds de la Recherche Scientifique-FNRS".

\section{References}

I. Wille G, Meyer D, Steinmetz A, Hinze E, Golbik R, Tittmann K: The catalytic cycle of a thiamin diphosphate enzyme examined by cryocrystallography. Nat Chem Biol 2006, 2:324-328.

2. Makarchikov AF, Lakaye B, Gulyai IE, Czerniecki J, Coumans B, Wins $P$, Grisar T, Bettendorff $L:$ Thiamine triphosphate and thiamine triphosphatase activities: from bacteria to mammals. Cell $\mathrm{Mol}$ Life Sci 2003, 60:1477-|488.

3. Bettendorff L, Kolb HA, Schoffeniels E: Thiamine triphosphate activates an anion channel of large unit conductance in neuroblastoma cells. J Membr Biol 1993, I36:28I-288.

4. Nghiêm HO, Bettendorff L, Changeux JP: Specific phosphorylation of Torpedo 43K rapsyn by endogenous kinase(s) with thiamine triphosphate as the phosphate donor. FASEB J 2000, I 4:543-554.

5. Lakaye B, Wirtzfeld B, Wins P, Grisar T, Bettendorff L: Thiamine triphosphate, a new signal required for optimal growth of Escherichia coli during amino acid starvation. J Biol Chem 2004, 279: $17|42-17| 47$.

6. Makarchikov AF, Chernikevich IP: Purification and characterization of thiamine triphosphatase from bovine brain. Biochim Biophys Acta 1992, I I I 7:326-332.

7. Lakaye B, Makarchikov AF, Antunes AF, Zorzi W, Coumans B, De Pauw E, Wins P, Grisar T, Bettendorff L: Molecular characterization of a specific thiamine triphosphatase widely expressed in mammalian tissues. J Biol Chem 2002, 277: 13771 - I3777.

8. Lakaye B, Makarchikov AF, Wins P, Margineanu I, Roland S, Lins L, Aichour R, Lebeau L, El Moualij B, Zorzi W, et al.: Human recom- 
binant thiamine triphosphatase: purification, secondary structure and catalytic properties. Int J Biochem Cell Biol 2004, 36: $1348-1364$.

9. Bettendorff L, Wirtzfeld B, Makarchikov AF, Mazzucchelli G, Frédérich M, Gigliobianco T, Gangolf M, De Pauw E, Angenot L, Wins $\mathrm{P}$ : Discovery of a natural thiamine adenine nucleotide. Nat Chem Biol 2007, 3:2 I I-2I 2 .

10. Makarchikov AF, Brans A, Bettendorff L: Thiamine diphosphate adenylyl transferase from $E$. coli: functional characterization of the enzyme synthesizing adenosine thiamine triphosphate. BMC Biochem 2007, 8: 17.

II. Shikata H, Koyama S, Egi Y, Yamada K, Kawasaki T: Cytosolic adenylate kinase catalyzes the synthesis of thiamin triphosphate from thiamin diphosphate. Biochem Int 1989, 18:933-94I.

12. Miyoshi K, Egi Y, Shioda T, Kawasaki T: Evidence for in vivo synthesis of thiamin triphosphate by cytosolic adenylate kinase in chicken skeletal muscle. J Biochem (Tokyo) 1990, 108:267-270.

13. Makarchikov AF, Wins P, Janssen E, Wieringa B, Grisar T, Bettendorff $L$ : Adenylate kinase I knockout mice have normal thiamine triphosphate levels. Biochim Biophys Acta 2002, I 592:I I7-I2I.

14. Noma T: Dynamics of nucleotide metabolism as a supporter of life phenomena. J Med Invest 2005, 52:127-I36.

15. Brune $M$, Schumann $R$, Wittinghofer $F$ : Cloning and sequencing of the adenylate kinase gene (adk) of Escherichia coli. Nucleic Acids research 1985, I3:7139-7I5I.

16. Shioda T, Egi Y, Yamada K, Yamada M, Nakazawa A, Kawasaki T: Synthesis and accumulation of thiamin triphosphate in Escherichia coli cells expressing chicken cytosolic adenylate kinase. Biochim Biophys Acta I99I, I I I 5:36-4I.

17. Cronan JE Jr, Ray TK, Vagelos PR: Selection and characterization of an $E$. coli mutant defective in membrane lipid biosynthesis. Proc Natl Acad Sci USA 1970, 65:737-744.

18. Glembotski CC, Chapman AG, Atkinson DE: Adenylate energy charge in Escherichia coli CR34IT28 and properties of heatsensitive adenylate kinase. J Bacteriol | 98I, I 45: | 374- I 385.

19. Eckert T, Möbus W: Uber eine ATP:thiaminediphosphat-phosphotransferase - Aktivität im Nervengewebe. H S Z Physiol Chem 1964, 338:286-288.

20. Voskoboev Al, Luchko VS: Isolation and radiometric determination of rat liver ATP: thiamine diphosphate phosphotransferase activity. Vopr Med Khim 1980, 26:564-568.

21. Nishino K, Itokawa Y, Nishino N, Piros K, Cooper JR: Enzyme system involved in the synthesis of thiamin triphosphate. I. Purification and characterization of protein-bound thiamin diphosphate: ATP phosphoryltransferase. J Biol Chem 1983 258: II87I-II878

22. Voskoboev Al, Chernikevich IP: Biosynthesis of thiamine triphosphate and identification of thiamine diphosphate-binding protein of rat liver hyaloplasm. Biokhimiya 1985, 50:|42|-|427.

23. Chernikevich IP, Luchko V, Voskoboev Al, Ostrovsky YM: Purification and properties of ATP:thiamine diphosphate phosphotransferase from brewer's yeast. Biokhimiya 1984, 49:899-907.

24. Voskoboyev Al, Chernikevich IP, Luchko VS: Studies on thiamine diphosphate kinase (EC 2.7.4. I5) from brewer's yeast: purification and some properties. Biomed Biochim Acta 1987, 46:3-13.

25. Eder L, Dunant $Y$ : Thiamine and cholinergic transmission in the electric organ of Torpedo. I. Cellular localization and functional changes of thiamine and thiamine phosphate esters. J Neurochem 1980, 35:1278-1286.

26. Bettendorff L, Michel-Cahay C, Grandfils C, De Rycker C, Schoffeniels E: Thiamine triphosphate and membrane-associated thiamine phosphatases in the electric organ of Electrophorus electricus. J Neurochem 1987, 49:495-502.

27. Egi Y, Koyama S, Shikata H, Yamada K, Kawasaki T: Content of thiamin phosphate esters in mammalian tissues - an extremely high concentration of thiamin triphosphate in pig skeletal muscle. Biochem Int 1986, I 2:385-390.

28. Szyniarowski P, Lakaye B, Czerniecki J, Makarchikov AF, Wins P, Margineanu I, Coumans B, Grisar T, Bettendorff L: Pig tissues express a catalytically inefficient $25-\mathrm{kDa}$ thiamine triphosphatase: insight in the catalytic mechanisms of this enzyme. Biochim Biophys Acta 2005, 1725:93-102.

29. Peterson GL: A simplification of the protein assay method of Lowry et al. which is more generally applicable. Anal Biochem 1977, 83:346-356.
30. Bettendorff L, Peeters M, Jouan C, Wins P, Schoffeniels E: Determination of thiamin and its phosphate esters in cultured neurons and astrocytes using an ion-pair reversed-phase highperformance liquid chromatographic method. Anal Biochem I991, 198:52-59.
Publish with Biomed Central and every scientist can read your work free of charge

"BioMed Central will be the most significant development for disseminating the results of biomedical research in our lifetime. "

Sir Paul Nurse, Cancer Research UK

Your research papers will be:

- available free of charge to the entire biomedical community

- peer reviewed and published immediately upon acceptance

- cited in PubMed and archived on PubMed Central

- yours - you keep the copyright 